\title{
UN NUEVO RETRATO DEL CARDENAL INFANTE DON FERNANDO, CONMEMORANDO LA VICTORIA DE NÖRDLINGEN (1634)
}

POR

\author{
ENRIQUE GARCÍA-HERRAIZ
}

El cuadro reaparecido en el comercio de Madrid que se estudia no representa a Felipe IV sino a su hermano menor el Cardenal Infante, vencedor en Nördlingen. Revisa los inventarios y desecha la autoría flamenca. Concluye con la hipótesis muy probable de que éste sea el "cuadro del Archiduque", número 590 del inventario de Velázquez de 1660.

Palabras clave: Cardenal Infante; Archiduque de Austria; Batalla de Nördlingen; 1634; Inventario de Velázquez.

This portrait which reappeared on the Madrid art market, does not represent Felipe IV but his younger brother the Cardinal Infante, victor at the battle of Nördlingen. The author revises the inventories, rejects a Flemish attribution, and concludes that the most likely hypothesis is that it is the "painting of the Archduke", n. ${ }^{\circ} 590$ in Velázquez's 1660 inventory.

Key words: Cardinal Infante; Archduke of Austria; Battle of Nördlingen; 1634; Velázquez inventory.

En una subasta madrileña ha aparecido recientemente un retrato ecuestre del Cardenal Infante don Fernando, hermano del rey Felipe IV (o. $/ 1.102 \times 81 \mathrm{cms}$ ) (fig. 1). El catálogo lo atribuye al taller de Rubens sin mencionar procedencia. Parece venir de Gran Bretaña pues en el reverso del bastidor hay dos inscripciones en inglés: una a lápiz (S. XX) dice Philip IV of Spain copy of Velásquez; la otra, más antigua, a tinta parda, Philip IV of Spain (unknown). Aunque los dos hermanos han sido confundidos en más de una ocasión en inventarios y catálogos de subastas no cabe duda en este caso que se trata del hijo menor de Felipe III representado en la fausta ocasión de su victoria en Nördlingen (1634) al frente de los tercios españoles ${ }^{1}$. Viste el traje de ceremonia

\footnotetext{
${ }^{1}$ La batalla de Nördlingen fue una de las últimas victorias militares de España. Fue el Conde Duque de Olivares quien conociendo las cualidades excepcionales del infante don Fernando le encomendó la difícil misión de formar y conducir un ejército a través de los Alpes en 1633. Lo hizo y venció con la ayuda de los alemanes del emperador Ferdinand III a las tropas combinadas de los suecos de Gustavo Adolfo, los holandeses del norte de Flandes y los alemanes
} 


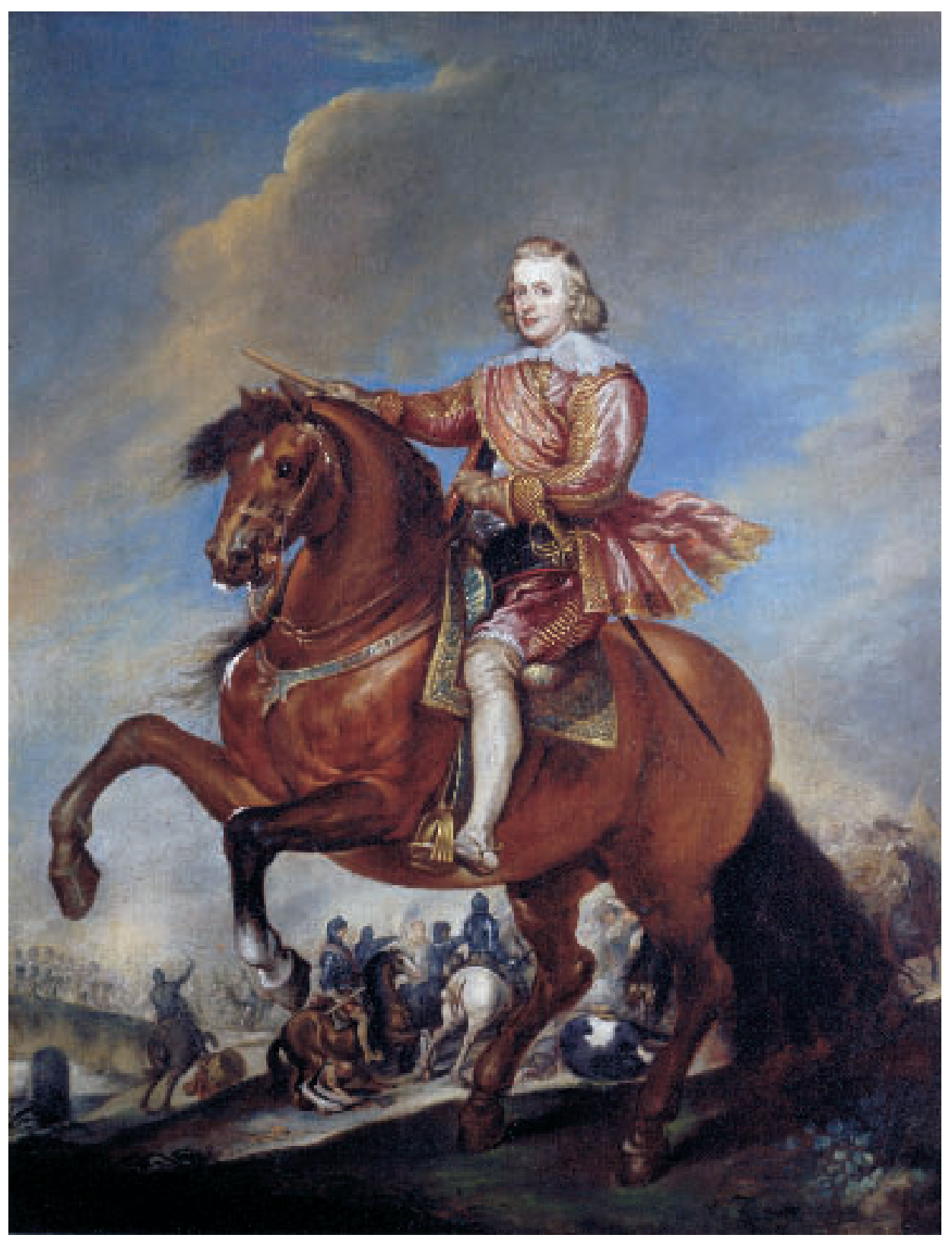

Fig. 1. Atribuido a Velázquez, Retrato ecuestre del Cardenal Infante don Fernando de Austria en la batalla de Nördlingen, colección particular Madrid. Fotografía (C) F. Martín.

protestantes, en este enclave del sur de Alemania en dos duras jornadas -5 y 6 de septiembre de 1634 - de lucha encarnizada. Alfred Michiels hace una excelente descripción de esta batalla y de la intervención decisiva del personaje a quien sin duda admiraba: “...la infantería y la caballería del Archiduque... decidieron la victoria cuando sonaba la hora del mediodía" (Alfred Michiels, "Van Dyck et ses éléves", Paris 1882, p. 415). (Ver también Elliott, John H., "El conde-duque de Olivares", Barcelona 2005, pp. 472-4). 


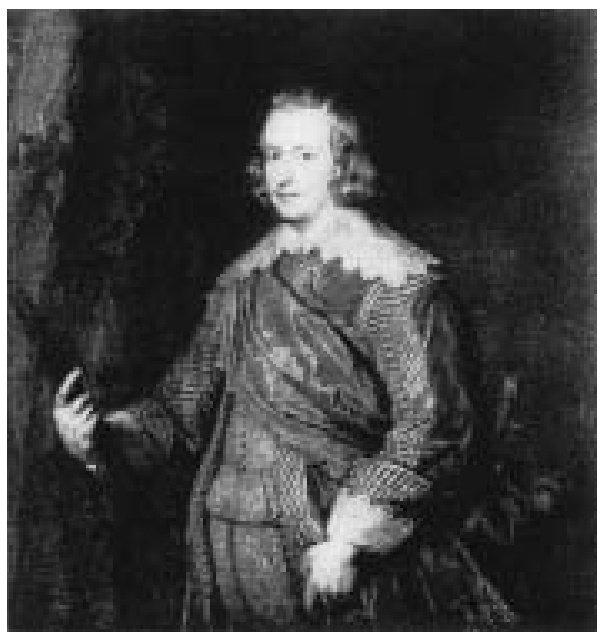

Fig. 2. Anton Van Dyck, Retrato del Cardenal Infante, Madrid, Museo Nacional del Prado.

con el que fue recibido triunfalmente en Bruselas el 4 de noviembre del mismo año, igual al del retrato de algo más de medio cuerpo que le hizo Van Dyck en la misma época, hoy en el Museo del Prado procedente de las colecciones reales (fig. 2).

El cuadro tiene algunas restauraciones, en general bien hechas, perceptibles en el pecho del caballo y en el cielo con zonas barridas de pintura o planas. La cola parece haber perdido pigmento mostrando bajo el foco la coloración roja de la preparación.

En la escena de la batalla, abajo, destaca un caballo en corveta con un jinete con bastón de mando que claramente está copiado del gran retrato ecuestre de Felipe IV, de Velázquez, del Museo del Prado (fig. 3).

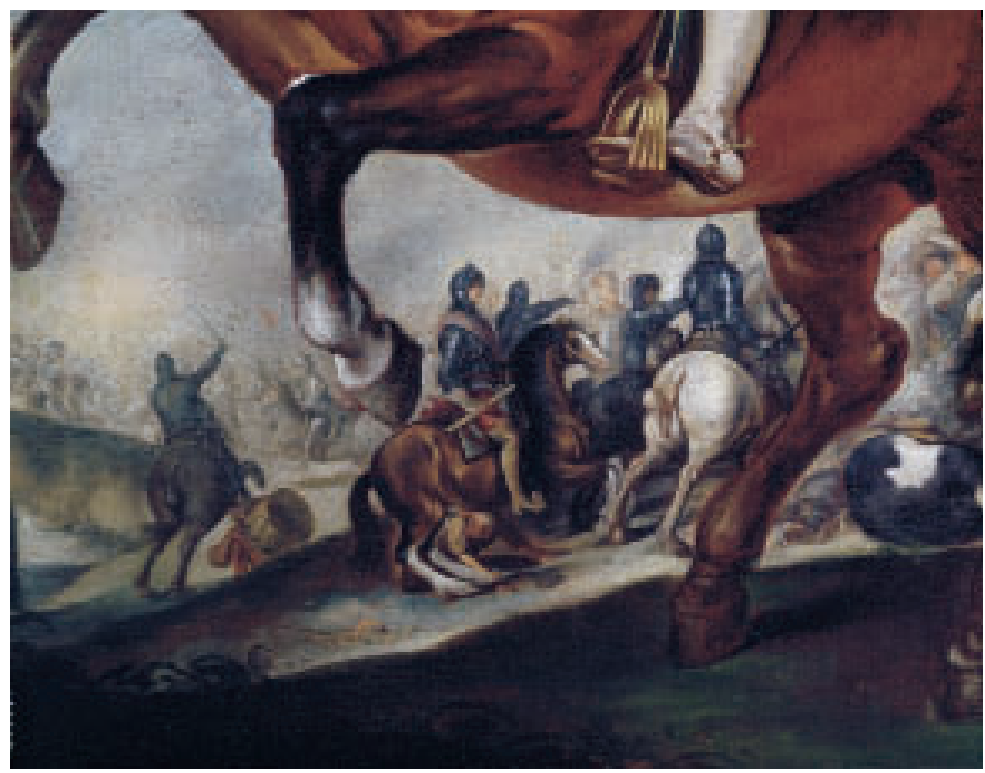

Fig. 3. Retrato ecuestre del Cardenal Infante... Detalle del fondo con jinetes. Fotografía (C F. Martín. 


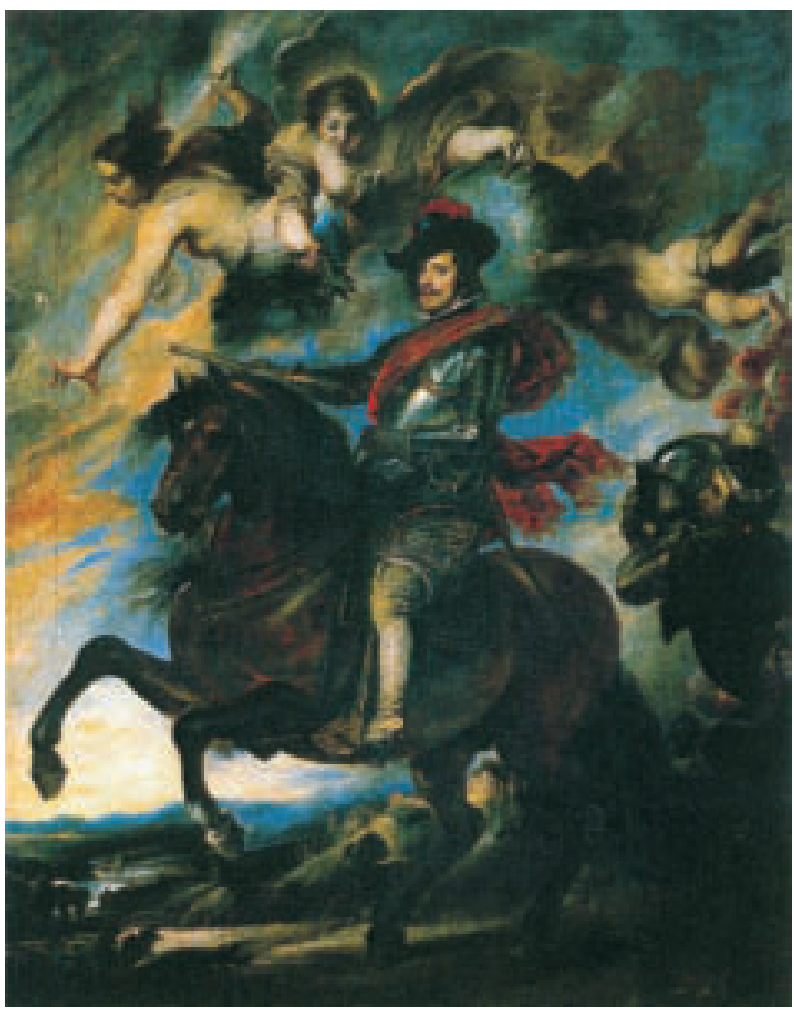

Fig. 4. Copia del Retrato ecuestre de Felipe IV de Rubens, Florencia, Galería de los Uffizi.
También es patente que el caballo y la postura del jinete se derivan del retrato ecuestre de Felipe IV, de Rubens, que el Rey tenía en el Salón del Trono y que desaparecido desde el incendio del Palacio Real en el siglo XVIII, sólo se conoce por la copia de los Uffizi (fig. 4).

Ya se ha indicado que el traje del caballero es similar al que viste el Cardenal Infante en el retrato de Van Dyck del Prado.

En el Prado está también el gran retrato ecuestre del Cardenal Infante con armadura de Rubens, igualmente conmemorativo de la victoria de las tropas imperiales sobre las protestantes en Nördlingen. El cuadro no se integró en la colección de Felipe IV ni llegó a Madrid hasta después de la muerte de Rubens cuando fue adquirido en la almoneda del gran pintor en 1645 (ver "Velázquez, Rubens y Van Dyck", 1999, Catálogo de la exposición comisariada por Jonathan Brown, p.136, texto de Alejandro Vergara que da el año 1661 para su integración en las colecciones reales) (fig. 5).

Anotemos desde el principio la sospechosa mala fortuna que acompaña a todos los retratos ecuestres que celebran la fugaz gloria político militar de aquel infante destinado por su padre, por razones estrictamente económicas, al cardenalato desde que fuera nombrado primado de España a los diez años de edad por el Papa Paulo V. Nombrado gobernador de los Países Bajos españoles adquirió el título honorífico de archiduque como sucesor y cabeza principal de la llamada corte archiducal de Bruselas, vacante por la muerte de Isabel Clara Eugenia. Murió pronto y joven, en 1641, sin haber regresado nunca a Madrid desde su salida de la corte en abril de $1632^{2}$. En Bruselas, desde que se incorporó a su importante cometido de regente de Flandes, se ocupó diligentemente en cumplir los encargos de pinturas de su hermano el rey coleccionista de arte que le apremiaba para que vigilara la actividad de Rubens sobre todo, pero también de su discípulo principalísimo Van Dyck quien era cortejado sin cesar por el rey inglés Carlos I.

Repasando las cartas en las que don Fernando informaba al rey, encontramos una relativa a los envíos para la Torre de la Parada que puede tener relación con el retrato que estudiamos aquí. El 30 de junio de 1638 escribe lo siguiente: "La memoria de las pinturas que V.M. manda se hagan nuevas he dado yo mismo a Rubens... con todo acuerdo a V.M. me paga mandando a Velásquez se de priesa al retrato, que le estimaré como devo y es razón." (Rooses et Ruelens, "Correspondance de Rubens..." vol.VI p.220). Es decir, que Velázquez parece estaba ocupado en hacer un retrato de Fernando en junio del año 38. No puede referirse al retrato de cazador

2 AEDo, Diego de, "El memorable y glorioso viaje del infante cardenal don Fernando de Austria", Amberes 1635, citado por Gue Trapier, E. de, Velázquez, New York 1948, p. 193 y casi todos los autores.

AEA, LXXXIII, 330, ABRIL-JUNIO 2010, 159-172, ISSN: 0004-0428 


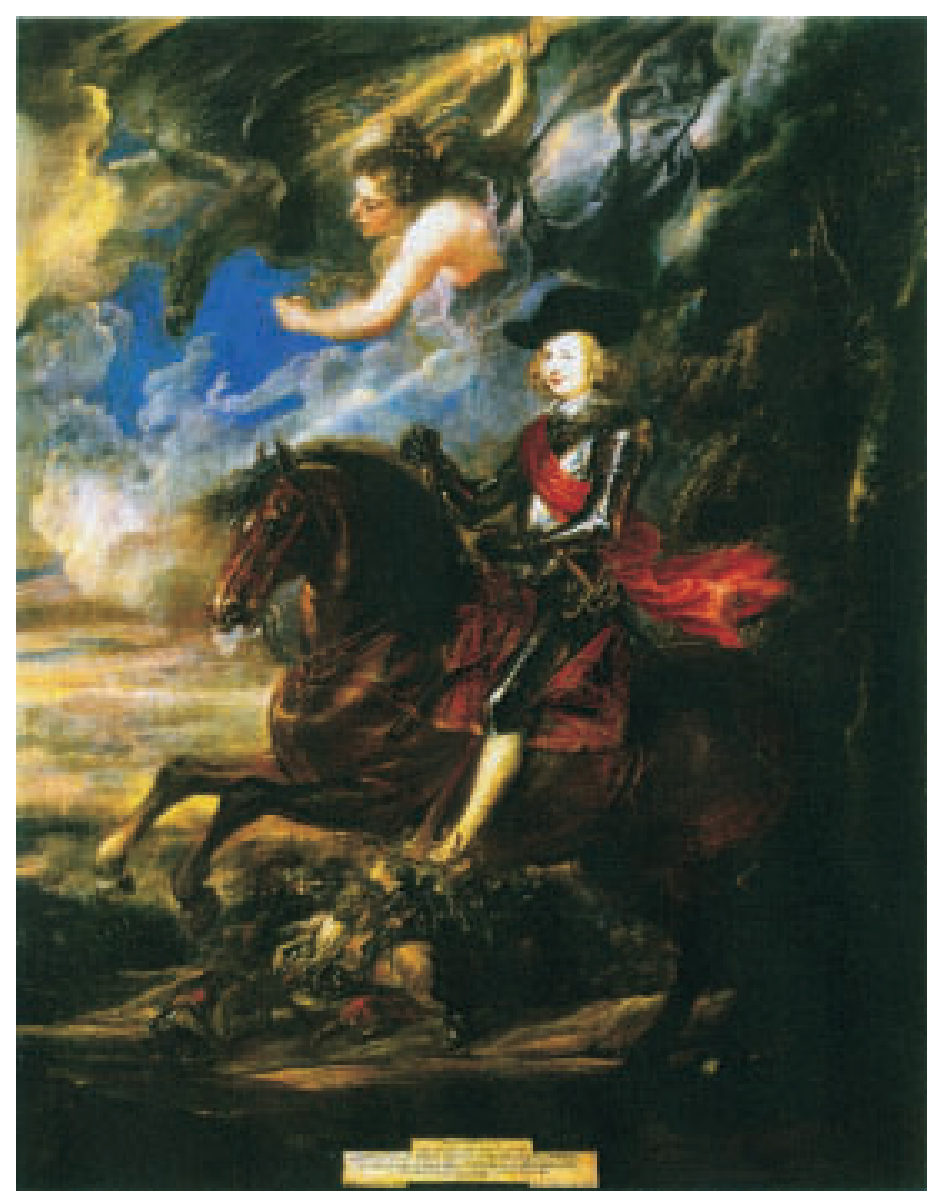

Fig. 5. Peter P. Rubens, Retrato ecuestre del Cardenal Infante en Nördlingen, Madrid, Museo Nacional del Prado.

que le había hecho en Madrid in situ (Museo del Prado), pues aunque este cuadro según los autores parece reflejar modificaciones en el paisaje que sugieren una época posterior a la hechura de la juvenil cabeza, el contexto de la carta apunta más bien a un nuevo cuadro que desea lo termine pronto para que lo reciba él mismo. No tendría sentido que a don Fernando le importe si Velázquez está añadiendo o quitando algo de un retrato que no le pertenece y menos que le pida al rey que se dé prisa en terminarlo. En una carta anterior, de 6 de abril del mismo año, después de anunciar que las pinturas ya han pasado de París y que "Dios quiera se haya acertado en toda la obra" hace una alusión confusa a un retrato suyo: "y el mío suplico a V.M. con todo encarecimiento me lo mande pagar enviándome un retrato de V.M. muy bueno, que seis años de faltar de los pies de V.M. de quien se ha criado a ellos, no puede tener otro consuelo, ya que el principal me falta...” ¿Está Fernando pidiendo a su hermano el rey que a cambio de su retrato le envíe uno suyo para consolarse de su ausencia? Entonces este retrato no puede ser el que le hizo Van Dyck en Bruselas y llevó a España el marqués de Leganés poco después de su entrada triunfal. Hay otro retrato al que alude otra carta de 22 de julio de 1639, "Mi retrato lleva este ordinario, que no ha sido poco tenga fin según la flema de esta gente". Éste es el de 
Gaspar de Crayer, vestido de cardenal, como el propio don Fernando constata en su carta de 10 de junio de $1640^{3}$.

Los autores en general se concentran en el retrato del Cardenal Infante de Van Dyck, del museo del Prado, ignorando si hubo alguno más de este pintor o aluden sólo de pasada a los ecuestres como es el caso de Christopher Brown: "Van Dyck le hizo un número de retratos...: en traje de cardenal, en el retrato del Prado; en armadura de tres cuartos en la colección Liechtenstein, y a caballo (Van Dyck, Christopher Brown, Yale University Press, p. 153). Por su parte Susan Barnes, Nora de Porter, Oliver Millar y Horst Vey en su ambiciosa obra-catálogo "A concise catalogue of Van Dyck", del 2002, incluyen bajo el número correspondiente a la obra "Cardenal Infante Fernando de España", del Museo del Prado (núm. III.83), lo que llaman "repetitions" de este retrato y copias y "variantes" del mismo entre las que se cita una copia vendida en Christie's, Londres 16-XII-1998 y "otro alargado al tamaño natural con una vista de la batalla de Nördlingen de $200 \times 139,5 \mathrm{~cm}$ ", que sería muy interesante comparar con el nuevo cuadro. También referencia que en 1741 y 1754 una pintura del Cardenal Infante a caballo fue subastada en Amberes, mencionando sin más la obra de Lionel Cust "Anthony Van Dyck. A historical study of his life and works", Londres 1900. Cust cataloga tres retratos de "Ferdinand, Cardinal Archduke of Austria" (el del Prado traído a España por el Marqués de Leganés; el de tres cuartos con armadura de la Galería Liechtenstein de Viena y otro montado en un caballo blanco, exhibido en G.G. 1887 Feria, Emanuel, Conde de. Ver Pimentel (?) El Diccionario Benezit registra otro ecuestre, copia de Rubens por Van Dyck en el museo de Budapest (?) cuyo rastro se ha perdido.

Dos líneas de investigación se abren con posibilidades de llevarnos a nuestro objetivo de a quien asignar el cuadro reaparecido en Madrid. Por un lado, suponemos que Van Dyck pintó al Cardenal Infante no sólo en el retrato de algo más que medio cuerpo sino también a caballo en una pose más acorde con su rango de Gobernador de Flandes, como indica Erik Larsen que menciona uno localizado por Cust en la colección de Mainwaring de Oteley Park ("The paintings of Anthony Van Dyck", Luca Verlag 1988, p.255). Y por otro, es preciso averiguar todo lo posible sobre el retrato que Velázquez pudo haberle hecho hacia 1638 según la carta de don Fernando a su hermano antes citada. El examen de los inventarios revela incógnitas y descubre nuevos caminos.

En el inventario de los bienes de Velázquez hecho a su muerte en 1660 hay dos lotes hasta ahora no identificados: núm. 590, Un cuadro del Archiduque, y núm. 592, El Rey nuestro Señor en un cavallo castaño de vara de alto. Estos dos cuadros junto a otros siete decoraban la pieza llamada en el inventario la Bóveda que era el salón principal de la casa donde también se situaba la rica biblioteca del pintor. Sánchez Cantón, a quien seguimos ("Cómo vivía Velázquez" Separata de A.E.A. 1943), dice de este grupo de obras que "seguramente también habrían sido pintadas por el gran artista" aunque no conste "indicación alguna que dé luz". Sobre el cuadro del Archiduque manifiesta, "es dudoso si sería retrato de Alberto de Austria, fallecido hacía ya 40 años, o de Leopoldo Guillermo, vivo a la sazón". López-Rey ("Velázquez A catalogue raisoné of his oeuvre", Londres 1963) apunta que el 592 puede ser el cuadro preparatorio del retrato ecuestre grande, hoy en el Prado, y lo da por desaparecido. En cuanto al "cuadro del Archiduque" (núm. 338), López-Rey cita a Sánchez Cantón incorrectamente pues elimina la expresión "es dudoso"con la que éste último matiza su posible identificación. Ambos autores se olvidan del candidato más natural por contemporaneidad y cercanía familiar, don Fernando de Austria, cardenal infante que también fue archiduque. Es verdad que el título de Cardenal Infante se ha pegado al personaje de tal manera que ha relegado al más honorario de Archiduque, tradicional

\footnotetext{
${ }^{3}$ Otra carta de don Fernando al Rey digna de estudio es la fechada en Bruselas el 26 de mayo de 1639 en la que le agradece el retrato del Príncipe y luego le dice "El mío está ya acabado, pero los pintores de este país son más flemáticos que el sr Velásquez y asi dudo mucho pueda llevarlo este ordinario, porque ha pedido quinze dias para vestirle".
} 
de la casa de Austria. La razón puede encontrarse en la preponderancia del factor religioso en las contiendas militares de la época. Habrá que convenir, sin embargo, en que situándonos en el escenario del inventario parece razonable pensar que los encargados de éste, Martínez del Mazo y Fuensalida, designaran con el título de "Un cuadro del Archiduque" una imagen que muestra al infante don Fernando en su papel de archiduque y no en el de cardenal.

Los autores fechan el retrato ecuestre de Felipe IV, de Velázquez, entre 1628 (Mayer y Harris, pero sólo su comienzo) y 1636 (Allende-Salazar, López Rey y el Catálogo oficial del Prado) (fig. 6). La datación de esta pintura es determinante para la de nuestro cuadro dada la inclusión en él del detalle del caballo. Un cuadro con la imagen del Cardenal Infante y una escena de batalla tiene que referirse a Nördlingen necesariamente y como esta victoria militar española sucede en 1634, el retrato ecuestre de Felipe IV que suministra al pintor el modelo del caballito bajo las patas tiene que ser datado en este año o antes. $\mathrm{O}$ sea, que el nuevo cuadro lógicamente tiene que ser posterior y su autor tuvo que tener delante aquél y gozar de libre entrada a palacio.

¿Hay que excluir entonces a Van Dyck y a Crayer que no estuvieron nunca en Madrid? Se impone reducir el examen de los candidatos a figurar como posibles autores a los pintores que tuvieran acceso a los aposentos reales donde estaban los modelos en los que se basa esta composición, es decir: a) el retrato ecuestre de Felipe IV de Rubens, b) el retrato de Van Dyck cuya vestimenta es casi idéntica en este retrato y c) el retrato ecuestre de Felipe IV de Velázquez, de donde procede el caballo que figura en la batalla en la parte inferior del nuevo cuadro.

Por el lado de los misteriosos retratos ecuestres vandyquianos del Cardenal Infante nos encontramos varias interesantes menciones de cuadros en colecciones importantes del siglo XVII ("Collections of Paintings in Madrid 1601-1755" by Marcus Burke and Peter Cherry, Getty

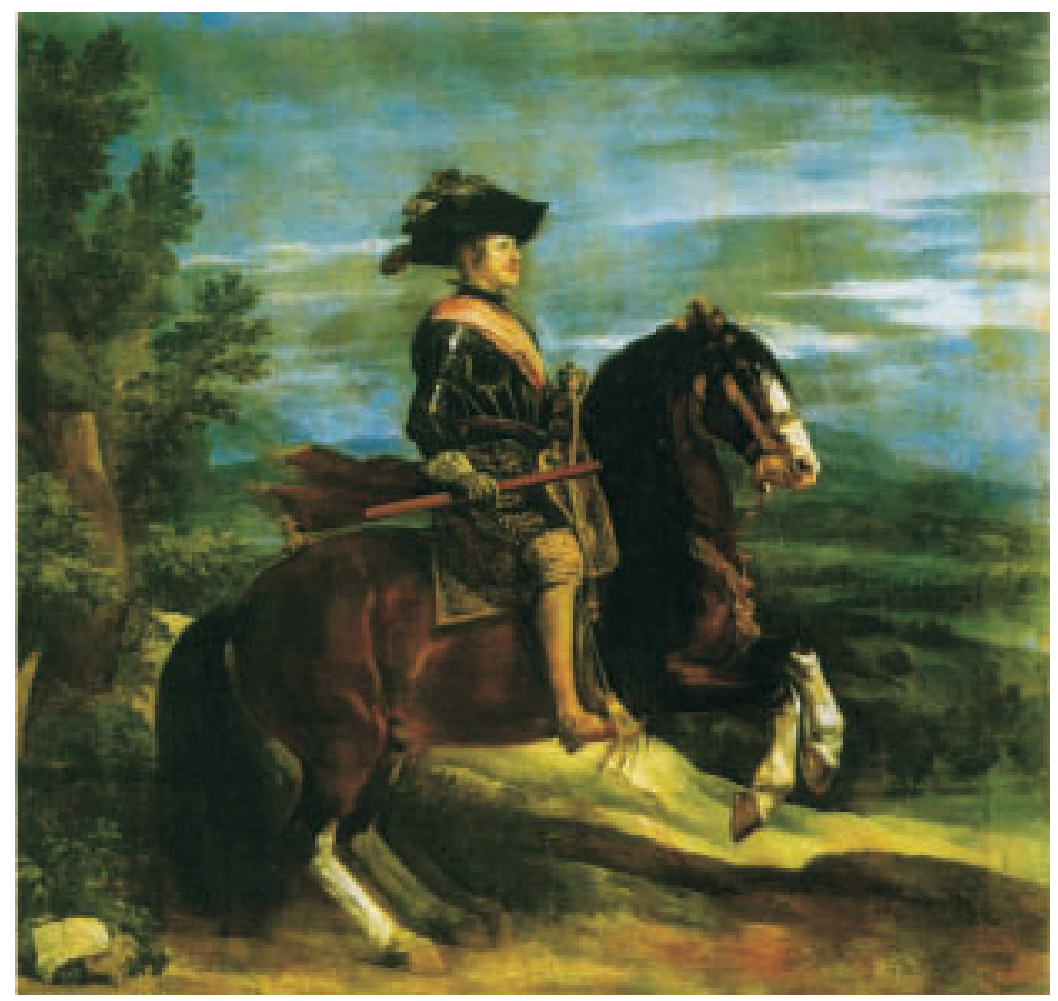

Fig. 6. Diego Velázquez, Retrato ecuestre de Felipe IV, Madrid, Museo Nacional del Prado. 
Foundation). El total de cuadros relacionados con el personaje según esta valiosa compilación asciende a 36 sin nombres de autor la mayoría, dos con la autoría de Van Dyck, uno de Rubens y otro de Crayer expresamente señaladas por los tasadores de los inventarios respectivos. Los de Van Dyck son, primero el de la herencia del Conde de Salvatierra don Joseph Salvador Sarmiento, Marqués de Sobroso, de 1682. Hizo la tasación don Antonio Palomino y dicen Burke y Cherry que "la obra más cara de toda la colección es un retrato ecuestre del Cardenal Infante don Fernando (n.24) por Van Dyck, valorada en 5.500 reales. Otros retratos reales de la colección fueron valorados sólo en una fracción de esta cantidad". "Un retrato del sr. Ynfante Cardenal puesto a cavallo de quatro baras de alto y tres varas más de ancho original de Bandique con su marco negro en quinientos ducados 5500". El otro cuadro de Van Dyck figura en la colección del marqués del Carpio de 1689, descendiente de don Luis Méndez de Haro, sobrino del Conde Duque de Olivares y también valido de Felipe IV: "Un Rettrato del Ynfante Cardenal a Cavallo en Un pais donde ay un Arbol grande donde está colgado un Letrero orig. De Vandique de quatro varas y quarta de caida y tres varas y terzia de Ancho con su marco negro en 33.000Rs". De los retratos ecuestres del Cardenal Infante sin mención de autor llama la atención uno del inventario de la misma Marquesa del Carpio de 1648 cuya descripción se ajusta muy cercanamente a nuestro cuadro con excepción de las medidas que son algo mayores: "Mas otro quadro pintado en medio del Sor Cardenal Infante a cavallo que es la batalla de Noslinguen de bara y tres quartas de alto $\mathrm{y}$ dos y dos terzias de ancho con su marco negro tasado en mil reales que valen treinta y cuatro mill maravedis". El tasador era Francisco Barrera que sólo da razón de los autores cuando son extranjeros.

\section{Conclusión}

Es evidente que queda mucho que estudiar sobre los retratos ecuestres del Cardenal Infante y despejar las dudas sobre los que aparecen atribuidos a Van Dyck en los inventarios. Casi todos los libros sobre Van Dyck aluden a la correspondencia del representante en Bruselas del rey Carlos I de Inglaterra, Gerbier, que le anunciaba el envío por Van Dyck de un retrato que éste había hecho del nuevo gobernador don Fernando de Austria. La posibilidad de que este cuadro fuera un retrato a caballo hay que abandonarla al existir evidencia de que el cuadro se identifica con el vendido en la almoneda real que pasa a Clarendon resultando ser la misma imagen del original de tres cuartos del museo del Prado.

Las conmemoraciones de la victoria de Nördlingen y el recibimiento en las principales ciudades flamencas del nuevo regente el año 1635 produjeron varios cuadros de homenaje a don Fernando de Austria aparte de los imponentes arcos triunfales de que se ocupó Rubens. En el museo de Viena se conserva el gran cuadro alegórico que hizo Rubens representando el saludo de los dos generales vencedores en aquella célebre batalla, el emperador Fernando III y el Cardenal Infante $\mathrm{y}$, sin duda impresionado por el relato que pudo haberle hecho personalmente éste, el gran artista y diplomático acometió la tarea de pintar la serie desperdigada hoy sobre el "Viaje del Príncipe" inspirado en los episodios del largo periplo militar de don Fernando incluyendo el paso de los Alpes, desde Barcelona a Milán, Nördlingen y Bruselas. Dos libros de diverso estilo son dignos de mención a nuestro objeto. Walter Liedtke con su popular compendio del tema del retrato ecuestre "The royal horse and rider: 1500-1800", Abaris Books, New York 1989, y Barbara Von Barghahn autora de "Philip IV and the Golden House of the Buen Retiro", Garland, New York and London 1986, disertación doctoral muy meritoria dirigida por López-Rey, que dedica a nuestro personaje atención especial, siguiendo a John R. Martin autor del estudio completo de las decoraciones para la entrada triunfal en Amberes en el volumen XVI del Corpus Rubenianum "The Decorations for he Pompa Introitus Ferdinandi". 
La repercusión en toda Europa de la gran victoria en Nördlingen elevó a su principal protagonista a categorías reservadas a los héroes de la antigüedad clásica. Cuando el nuevo archiduque envió a Madrid el maravilloso grupo de las siete estatuas de los Planetas, Olivares no pudo por menos de agradecérselo en carta de 20 de marzo 1637 prometiéndole que su memoria siempre será reconocida en el nuevo palacio del Buen Retiro. (Cita repetida por casi todos los autores y por Von Barghahn, Ibid., vol. 1215).

La cuestión de cómo se celebraría y si de hecho se llegó a celebrar la gloria del Cardenal Infante en el palacio del Buen Retiro es materia de debate que la última exposición del museo del Prado de 2005 "El Palacio del Rey Planeta: Felipe IV y el Buen Retiro" (Catálogo editado por Andrés Úbeda, Madrid 2005) no ha resuelto pues de hecho no la ha abordado. El estudio principal del catálogo "La reconstitución del Salón de Reinos. Estado y replanteamiento de la cuestión", de José Álvarez Lopera, se concentra exclusiva y brillantemente en dicho salón grande sin ocuparse de las piezas secundarias que también estaban decoradas con cuadros como era la antecámara del Salón de Reinos también llamada salón del Cuerpo de Guardia del Rey. Aquí debieron colgarse sendos retratos ecuestres grandes (tres varas y media de alto por dos varas y cuarto de ancho) del "Señor emperador Fernando III" y del Cardenal Infante, que el inventario de 1701, de donde toma la información von Barghahn, evalúa en 1.800 reales cada uno. Que hubo un propósito de conmemorar la victoria de Nördlingen lo acredita la tan citada carta del secretario de la legación toscana Monanni a sus superiores en Florencia (26 de abril de 1635) que, resumiendo, dice: "Ha hecho pintar (el conde-duque) para todas aquellas galerías historias y fábulas curiosas... doce cuadros con doce empresas del tiempo del Rey presente a saber... La victoria de Nördlingen, cuando se dieron estas órdenes no había tenido lugar aún, y no se logró sólo con las armas de aquí, sino también con las del emperador; sin embargo se pintará en otro salón majestuosamente para honrar al cardenal-infante" (versión del italiano de Alvarez Lopera en el catálogo citado). Brown y Elliott dan por sentado que un retrato a caballo del Cardenal Infante en Nördlingen, supuesta copia del cuadro de Rubens figuraba en la antesala del gran salón ("A Palace for a King”, Yale University Press 1980, p. 174) y M. D. Padrón también en su Catálogo de la Escuela Flamenca del Prado, p.276. Digo supuesta porque nada se sabe sobre este cuadro que difícilmente podía ser copia del de Rubens, si es cierto que éste no entra hasta 1661 en las colecciones reales. Von Barghanh conjetura sobre la probable existencia de una sala dedicada al Cardenal Infante con las pinturas procedentes de los arcos triunfales que el nuevo Archiduque enviaría desde Bruselas. Todo acabó cuando se firma en 1648 el tratado de Münster dando fin a la presencia de España en los Países Bajos.

Teniendo en cuenta que ninguna descripción y tamaño de los retratos ecuestres del personaje mencionados en los inventarios y catálogos se ajusta a los de la obra reaparecida y la circunstancia antes señalada de la presencia del caballito velazqueño, aconsejan eliminar a Van Dyck, Rubens y Crayer y concentrarnos en Velázquez y su entorno más próximo.

La calidad del conjunto y algunos detalles como son las hojas verdiazules de la esquina inferior derecha (a comparar con hojas muy similares del retrato ecuestre del Conde-Duque del Prado) (fig. 7), la cabeza de Fernando con el cabello rubio en suaves ondas que encontramos en varios retratos del rey, la manera suelta, directa con la que está resuelto el traje que no está copiado en detalle del modelo de Van Dyck ${ }^{4}$ sino interpretado con golpes y trazos de pincel del estilo característico de Velázquez y la naturalidad con la que está expresada la posición del caballero en su montura con el pie perfectamente engarzado en la espuela, el trazado de la empuñadura de la espada pintado sin vacilación y las claras concomitancias con el retrato del príncipe Baltasar

\footnotetext{
${ }^{4}$ Velázquez imita a Van Dyck en el retrato de Felipe IV de Fraga, de la Frick Collection de Nueva York. Compruebo que J. Brown y antes E. Harris opinan lo mismo en las obras antes citadas de dichos especialistas velazqueños.
} 
Carlos a caballo como es la disposición del terreno en franjas que descienden de derecha a izquierda, se acerca más a la autoría del maestro que a la de ninguno de sus coetáneos de la corte o seguidores (figs. 8, 9 y 10). Esta hipótesis de estudio puede resumirse así:

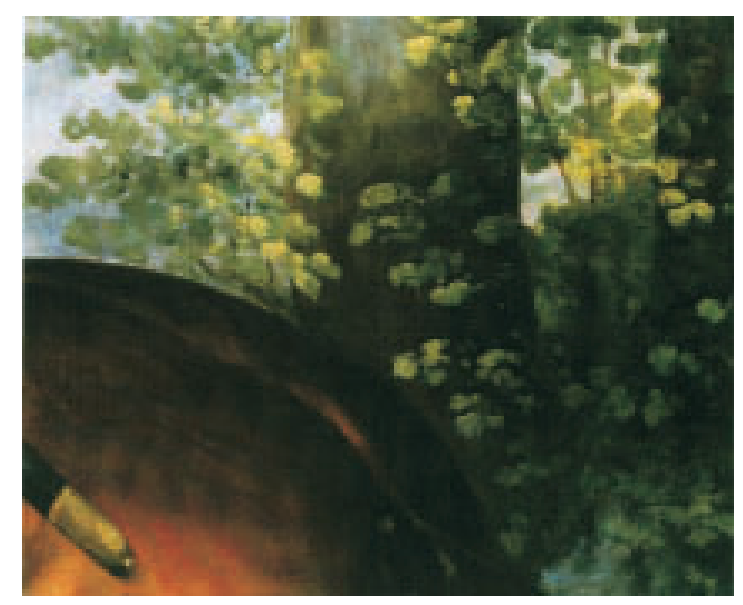

Fig. 7. Diego Velázquez, Retrato ecuestre del Conde Duque de Olivares, Madrid, Museo Nacional del Prado, detalle hojas parte inferior derecha.

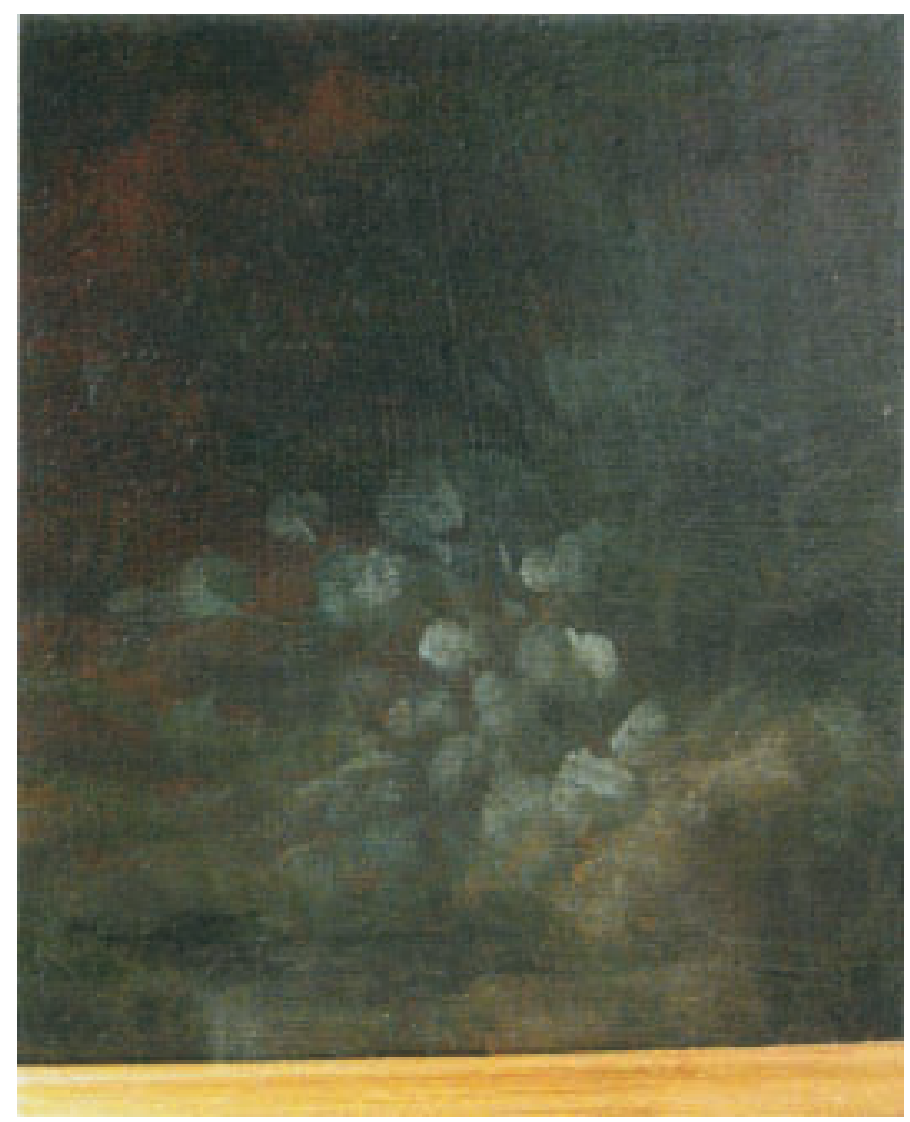

Fig. 8. Retrato ecuestre del Cardenal Infante. Detalles comparativos. 

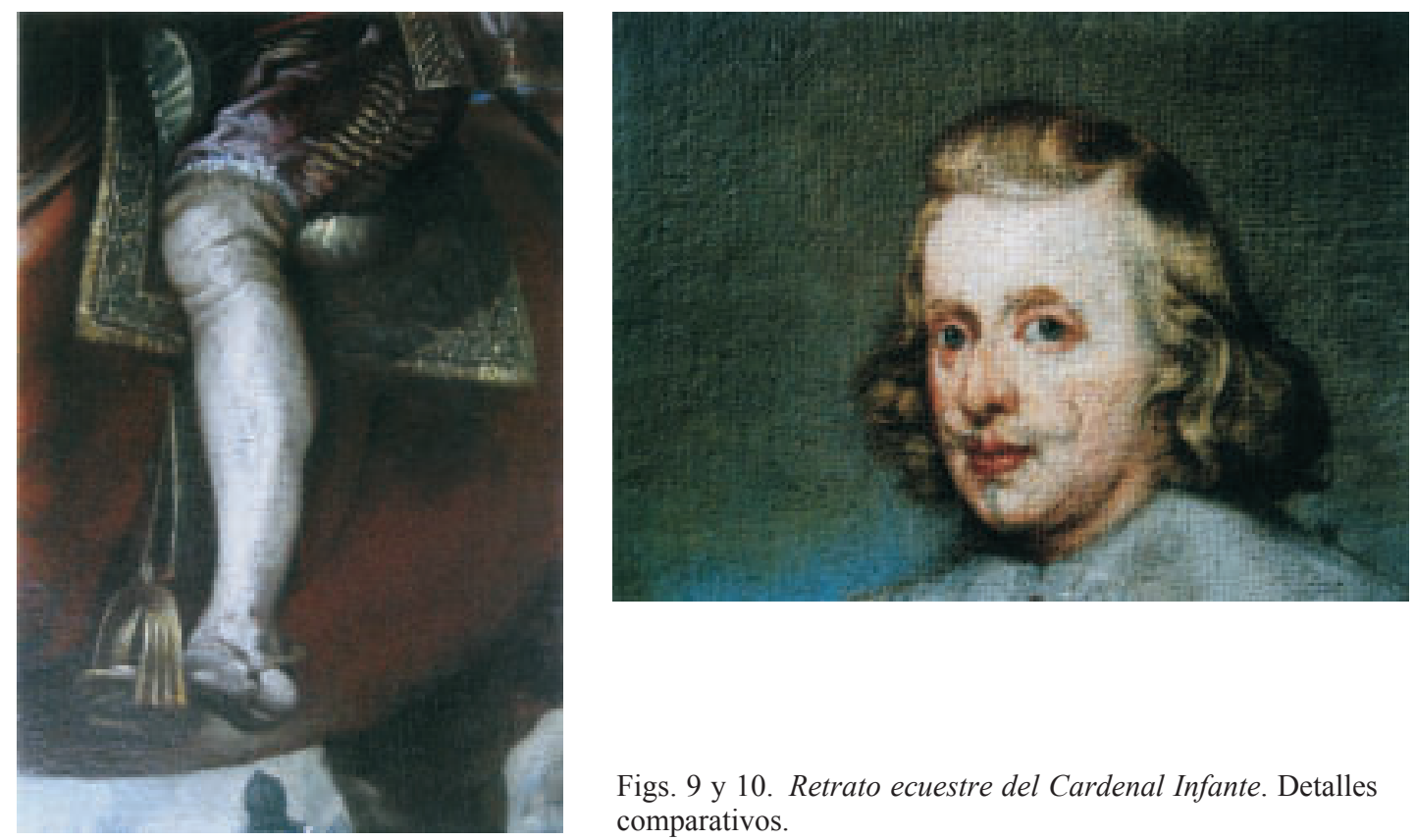

Figs. 9 y 10. Retrato ecuestre del Cardenal Infante. Detalles comparativos.

Velázquez quiere rendir su homenaje personal al infante a quien trató en la corte y sin duda admiraba por su victoria militar de Nördlingen. Le había hecho en Madrid un retrato de faz imberbe y cabello corto vestido de cazador (Museo del Prado) pero ahora conoce por el cuadro de Van Dyck que había traído Leganés (1635) una imagen diferente del nuevo archiduque ${ }^{5}$. Tiene también cerca y lo ve constantemente en sus labores palaciegas el gran cuadro de Rubens tan apreciado por el rey. Este caballo en corveta lo ha debido estudiar atentamente e incluso copiarlo imitando el proceder del artista flamenco a quien acompañó en sus visitas a las colecciones reales y observó como copiaba los cuadros de Tiziano en el Escorial ${ }^{6}$. Si Van Dyck le proporcionará

${ }^{5}$ Pérez Sánchez (Catálogo exposición Velázquez, Museo del Prado, 1990, pp. 270-4) en su comentario al "retrato del cardenal infante cazador colocado en el salón de cacerías de la Torre de la Parada en 1634" dice que "se trata del único retrato conocido de Velázquez de este hermano del rey Felipe IV...". En la controversia entre los autores sobre la datación de este cuadro se inclina en pensar que sea anterior a los otros dos compañeros representando al rey y al infante Baltasar Carlos. Curtis (Velázquez and Murillo, New York 1883, n. 145) lo fecha en 1628. Gudiol (Velázquez, 1974, p. 202 de la ed. inglesa) opina que la cabeza es de antes de la salida de don Fernando de Madrid en 1632 y el resto de años después. Pantorba (citado por Pérez Sánchez) señala su extrañeza de que Velázquez no hubiera pintado todavía en 1632 un retrato del infante "por cuyas puertas" había entrado en Palacio. Alude sin duda a lo que escribe Palomino en su vida de Velázquez del Museo Pictórico, que fue un camarero del Cardenal Infante quien llevó a Palacio por vez primera el retrato de don Juan de Fonseca, que gustó tanto al rey que llamó inmediatamente a Velázquez a su servicio. Sabido es, además, que el infante don Fernando poseía en su colección de arte el cuadro sevillano de Velázquez "El aguador", que luego cedería al rey. (Para un resumen de opiniones detallado ver MoRÁN, Miguel y SÁNCHEz Quevedo, Isabel, "Velázquez Catálogo completo", Akal 1999, p. 160.)

${ }^{6}$ La copia de los Uffizi, tenida generalmente por autógrafa, de Velázquez sólo en la cabeza según el prototipo del retrato de Fraga, merece una reconsideración muy seria en la línea marcada por el viejo libro de Curtis que consideraba este cuadro original cierto de Velázquez excepto en las alegorías. Para mí, el caballo no es un ejemplar típico del barroquismo exaltado de Rubens si lo comparamos sin prejuicios con otros equinos célebres de su producción: El trepidante caballo del San Jorge y el dragón, el nervioso alazán que monta el altivo duque de Lerma e incluso el que sirve de airosa montura al Cardenal Infante con los ojos que parecen salirse de sus órbitas son muy diferentes. Aunque simpatizamos 
el modelo para la cabeza y el traje, Rubens le suministrará los del corcel y la postura del jinete. El conde-duque pudo, a su vez, haber concebido el proyecto de realizar un cuadro grande para homenajear la gloria militar del infante Fernando a fin de formar pareja con el retrato ecuestre del rey de Rubens que desplazó el que Velázquez mismo había hecho a su llegada a la corte. Éste empieza el proyecto prudentemente pintando sólo un cuadro pequeño de una vara aproximadamente de alto. Pero Velázquez, pintor real, desea hacer partícipe en la conmemoración al mismo rey y decide integrarlo en la batalla en espíritu, representándolo por su caballo y montado por una figura casi enmascarada por la celada ${ }^{7}$ ¿ ¿Quién excepto el mismo Velázquez se hubiera atrevido a una libertad semejante? No es ilógico imaginar que existiera complicidad entre el rey y su pintor en la ejecución del singular retrato del hermano ausente, pues es sabido que el rey visitaba al artista y según Palomino "disponía de llave y silla para verle pintar" en su obrador. Pero hay más. Frances Huemer, en su enjundioso estudio del retrato perdido de Rubens (Corpus Rubenianum Portraits I, Antwerp, 1972, p.73), publica una fotografía de "una copia pequeña del siglo diecisiete de sólo el caballo y el jinete frente a un paisaje, que es muy importante porque muestra al rey de veintidós años con sombrero de plumas blancas, probablemente tal como Rubens lo presentaba originalmente en la pintura de 1628, pero que está desaparecida" (fig. 11). Repasando el López-Rey encuentro que incluyó este cuadro desaparecido en su libro de 1963 (ibid., núm. 197, fig. 239) e incluso ya en su artículo de La Gazette des Beaux Arts, Jan. 1959, antes que Huemer, quien no le cita, reproduciendo la misma fotografía procedente del libro dedicado a Velazquez por Mayer ("Velázquez", Londres 1936, núm. 196). Vuelva el crédito a su dueño pues fue el perspicaz historiador alemán quien primero publicó esta fotografía del misterioso cuadro. Y también lo registra Enriqueta Harris (sin citar procedencia) con la misma ilustración ("Velázquez" Phaidon, London 1982, p.68). Observamos que aquí el rey Felipe tiene, en efecto, cara de joven, las plumas del sombrero son blancas tal como lo describe el inventario de Palacio de 1636. ¡Pero lo más notable es que Mayer y López-Rey dan las medidas $1 \mathrm{~m} \times 0,80 \mathrm{~m}$ que coinciden casi exactamente con las del nuevo cuadro del hermano del rey! El copista debió ser alguien que no gustaba de alegorías de mujeres volando: Velázquez es el candidato lógico. En cuanto al autor, López-Rey dice, "probablemente pintado por un discípulo de Velázquez", mientras que Huemer cree que alguien copió a Rubens imitando el estilo de Velázquez. Mayer dice, "ciertamente un discípulo de Velázquez, quizás Mazo". Harris "probablemente contemporánea hecho en el estudio de Velázquez". Para mí, esta "copia pequeña” perdida es aún más velazque-

con la opinión de Huemer nos inclinamos a pensar que fue el mismo Velázquez quien trazó, por lo menos, las pinceladas definitorias de todo el cuadro, y especialmente del animal, aunque luego fuera acabado por un pintor del taller que no es probable se trate de Mazo ya que figura tachado su nombre en el inventario de Gaspar Méndez de Haro de 1651. En realidad existe la posibilidad -como apunta López-Rey en su artículo de La Gazette des Beaux Arts- de que fuera el propio Velázquez, recién regresado de Italia, el responsable de la tachadura y de la corrección que dice "copia de Rubens y la cara del Diego Velazquez" (Burke and Cherry, n. 49:0228). Estas palabras admiten una interpretación en el sentido de que Velázquez copió el cuadro de Rubens pero que la cara (la cabeza) no la copió sino que era original de él mismo. En cualquier caso resultó un caballo más velazqueño que rubeniano. De aquí proceden los caballos de los retratos de Felipe IV, del Conde Duque y del Príncipe Baltasar Carlos, tesis en la que coincido con Huemer y con mi viejo admirado Martín Soria ("Art and Architecture in Spain and Portugal”, Baltimore, 1959 p. 384, n. 23, citado por Huemer). No olvidemos que el cuadro, antes de pasar a los Uffizi, estuvo durante el siglo XVII en el Palazzo Pitti como Diego Velasco, según cita de Mayer siguiendo a Curtis. Es curioso que las posiciones más antagónicas sobre la intervención de Velázquez en el cuadro de los Uffizi estén protagonizadas por dos escritores estadounidenses separados por un siglo de distancia: Curtis a favor y Brown en contra, pues este último ni siquiera admite la cabeza ("Velázquez pintor y cortesano" p. 289). Harris tampoco reconoce la mano de Velázquez en la cabeza (Ibid., p. 68).

${ }^{7}$ La idea de incorporar al rey en la conmemoración de un triunfo militar aparece en el cuadro de Maino "La reconquista de Bahía" (Museo del Prado) donde se ve al monarca representado en un tapiz lateral acompañado por el Conde-Duque que ayuda a colocarle una corona de laurel. 
ña y más temprana que la de los Uffizi y confirma por la identidad del tamaño la hipótesis de la pareja fraterna de cuadros. Pudo haber existido un proyecto originado por Olivares o por el mismo rey de emparejar a los dos hermanos en retratos ecuestres semejantes. En esta hipótesis el cuadro reaparecido sería el modelo propuesto para celebrar a don Fernando y el conocido sólo por fotografía el destinado al rey. El adverso curso de los acontecimientos posteriores a Nördlingen difuminó este plan, que se abandonaría, quedando sólo los cuadros preparatorios.

Fig. 11. Retrato ecuestre de Felipe IV con sombrero de plumas blancas. Paradero desconocido.

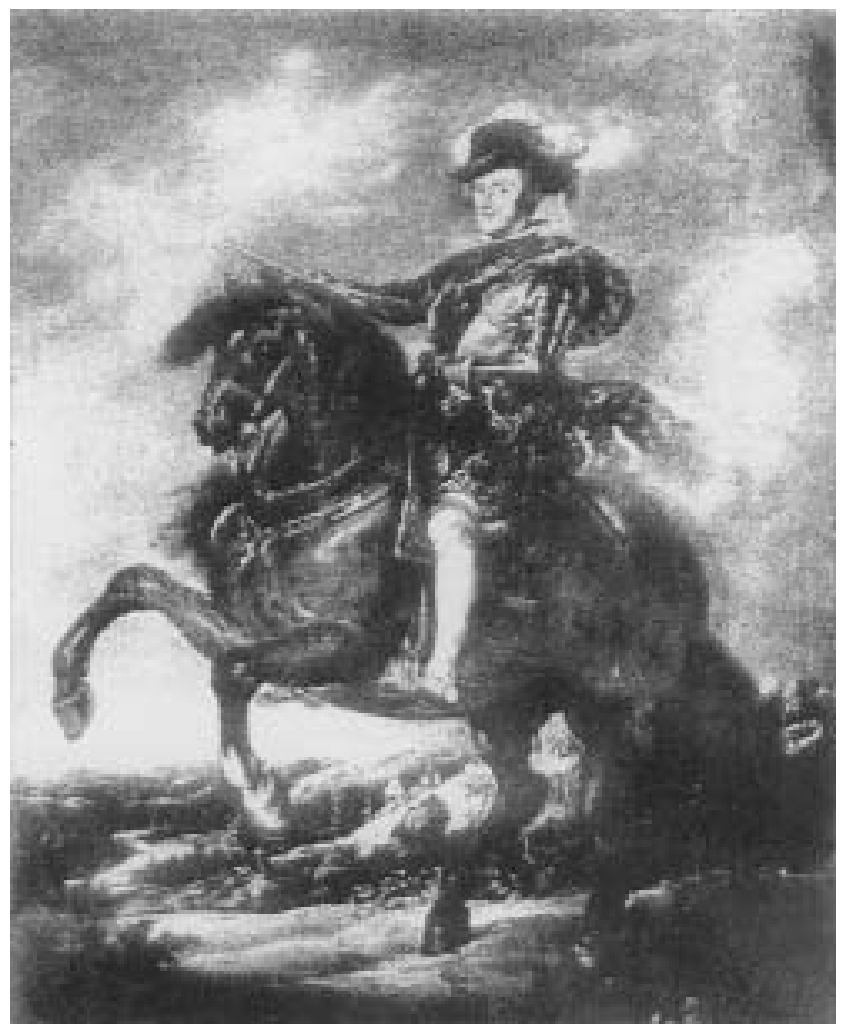

Concluyamos la hipótesis histórica: Al morir tan pronto don Fernando sin haber regresado nunca a Madrid, el retrato quedará en poder de su autor, Velázquez, y en sus aposentos lo encuentran (junto al cuadro que hacía pareja) los encargados de su inventario a su muerte. Lógicamente, Mazo queda descartado y Carreño también por ser éste muy posterior ya que no es pintor de cámara hasta después de la muerte de Felipe IV. Van der Hamen, que hizo cuadros para el infante don Fernando según documentos publicados por Jordan (W.B. Jordan "Juan de Van der Hamen y Leon, Patrimonio Nacional 2006, p.262), tampoco puede ser candidato pues murió en marzo del 1631. El cuadro del "Rey nuestro señor..." (núm. 592 del inventario) queda así también identificado con el que se conoce sólo por la fotografía descubierta por Mayer (fig. 11). Velázquez habría conservado en la sala noble de su casa, hasta su muerte, los modelos de un proyecto fallido, honrando así a los dos personajes a quienes él mismo estaba más agradecido.

Fecha de recepción: 15-I-2009

Fecha de aceptación: 15-VII-2009 